\title{
Flexural resistance of the polypropylene fibres reinforced cement mixes with waste material
}

\author{
Samer Abou Kheir ${ }^{\prime \prime}$, Jad Wakim ${ }^{l}$, and Elie Awwad ${ }^{l}$ \\ ${ }^{1}$ Scientific Research Center in Engineering (CRSI), Lebanese University, Faculty of Engineering, Branch II, Roumieh- Mount \\ Lebanon. *Graduate Student.
}

\begin{abstract}
The polypropylene (PP) fibers in shotcrete has been used for ground support and building strengthening, since several decades. However, the recent trend is to use the waste material in cementbased mixes to produce an eco-friendly material. Such waste material is the incineration fly ash (FA) that is classified as a hazardous product. This study is intended to establish the mechanical properties of fiber reinforced mortar in addition to cement or sand partial replacement by fly ash, in terms of flexural strength testing. The mechanical properties reflect the influence of the dosage of fiber content and the proportion of the fly ash on the flexural strength. The percentage of cement or sand was replaced by $0,10,20$, and $30 \%$ fly ash. The dosage of fibers was $0,0.6,1.2$, and $1.8 \mathrm{~kg} / \mathrm{m}^{3}$. This green mix with fibers provides a partial substitute of cement as it is cheaper, by incorporating waste product, and saving energy consumption in the production. Due to growing interest in sustainable construction, engineers and architects are motivated to choose such materials which are more sustainable.
\end{abstract}

\section{Introduction}

Fibre reinforced shotcrete has been successfully used in different civil engineering applications. Concrete and cementitious materials are vulnerable to tensile crack developing in structural element. Reinforcing materials with fibers are commonly used to control tensile cracks. The advantage of fibers in mortar is characterized by the ductile behaviour, namely better post-cracking strength and energy absorption that is referred to as "toughness". The use of fibers provides resistance to plastic, drying shrinkage, and controls crack width at a dosage as low as $0.25 \%$ [1], and fibers delay crack formation and reduce crack widths and total cracking areas.

The recent trend is to reduce $\mathrm{CO}_{2}$ emission and to recycle waste material such as waste to energy fly ash. One example of fly ash, which is composed of black particles, is retained on chimneys filters and generated by the combustion of paper, nylon, and plastics. The present research aims to find the optimum replacement percentage and satisfactory mechanical properties.

Meanwhile, Lebanon is suffering from garbage crisis being unable of establishing a sustainable garbage recycling system. One of the proposed solutions is to build incinerators across the country, and burn all the garbage produced without any suitable disposal plan.

The effect of compressive strength on mixes for cement replacement with fly ash is well observed at early age and after 28 days [2]. The increase of strength is $50 \%$ for concrete containing fly ash and $30 \%$ for concrete without fly ash [3]. The compressive strength can decrease with the increase of the fly ash replacing cement at 7, 28 and 56 days depending on the fly ash content in the range between $0 \%$ and $60 \%$ [4]. The mechanical properties of concrete mixture with fly ash replacing sand at different content ranging from $10 \%$ to $50 \%$ indicate a significant improvement in the compressive and flexural strengths on concrete with fly ash replacing sand [5]. The compressive strength increases proportionally with the increase of polypropylene fibers and reach $12 \%$ of increasing for $2 \%$ of fiber content [6]. A slight increasing of the flexural strength was also noted on mortar samples containing a small volume fraction of polypropylene fibers and can reach the optimum strength for $0.3 \%$ of fibers in term of volume content.

The flexural strength could decrease with the ratio of fly ash replacing cement (FAC) at 7 days and no optimum was observed. Otherwise, higher flexural strength was observed for 10\%, 20\% and 30\% FAC in comparison with the control $\operatorname{mix}[7]$. 
In the present study, we aim to study the flexural resistance of modified mortar with different dosage of waste fly ash and to understand the effect of the polypropylene fibers in the mixes. Samples testing were performed in the laboratories of the Lebanese University, Faculty of Engineering Branch II. Several mixes and tests were considered.

\section{Materials}

Materials used in the experimental testing and methodologies of works are defined below:

\subsection{Cement and Aggregates}

Ordinary Portland cement was used, grade P 42.5 type I, with 6 to $15 \%$ of limestone content. The fineness and specific gravity of the cement used were respectively equal to $3,174 \mathrm{~cm}^{2} / \mathrm{g}$ and 3.15 . Aggregates consisted of sand aggregates passing sieve no.4 and retained on sieve no. 200. Sand equivalent is equal to $80.6 \%$ and satisfied the gradation recommended by the ASTM C33 [8].

\subsection{Polypropylene Fibers}

Fibers are polypropylene (PP) fibers and can be classified as microfibers. The thickness of fiber is 18 microns, the length is $6 \mathrm{~mm}$, the tensile strength ranges from 300 to $400 \mathrm{MPa}$, the elastic modulus is $4000 \mathrm{MPa}$.

\subsection{Fly ash}

Fly ash (FA) was obtained from a local power plant in Lebanon. The fly ash is produced from the combustion of plastics, paperboards, and nylon, and it is captured by filters before reaching power plant chimney. Based on the chemical composition of the fly ash, we can conclude that the type is $\mathrm{CH}$ class due to high content of $\mathrm{CaO}(21.3 \%)>$ $20 \%$, which is higher than the allowed limits.

\subsection{Superplasticizer}

Superplasticizer was used in all mixes to produce a free-flowing mix with low water content, in order to reach high early strength. $1 \%$ superplasticizer were added to the mixes containing $0 \%, 10 \%, 20 \%$ FA content, while $1.5 \%$ superplasticizer were added to the mixes with $30 \%$ of fly ash content to overcome the decrease of workability with the increase of the fly ash content in the mix.

\section{Flexural testing on prisms and experimental procedures}

The $40 \times 40 \times 160 \mathrm{~mm}$ beam specimens were tested according to the ASTM C348 [9]. The load is applied in the middle span of the specimen and the speed rate is $2 \mathrm{~mm} / \mathrm{min}$. The below figure shows the prism beam mounted on the testing machine.

Fig. 1. Flexural beam testing

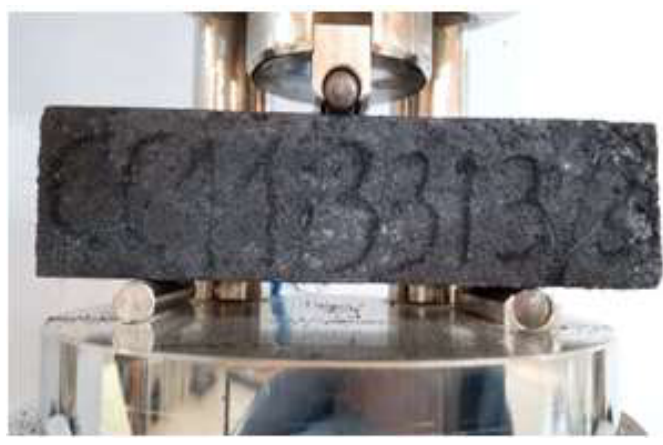

The experimental program includes three variables: FA-Cement replacement, FA-Sand replacement, and PP fiber content. Twenty-eight mixture proportions were made as indicated below:

- Control mix (without fly ash and without PP fibers).

- Three mixes with fly ash replacing cement, without PP fibers. 
- Three mixes with fly ash replacing sand, without PP fibers.

- Three mixes with PP fibers, without fly ash.

- Nine mixes with 10\%, 20\%, and 30\% FA-cement replacement (by weight), and $0.6,1.2$, and $1.8 \mathrm{~kg} / \mathrm{m}^{3}$ of fiber content.

- Nine mixes with 10\%, 20\%, and 30\% FA-Sand replacement (by weight), and $0.6,1.2$, and $1.8 \mathrm{~kg} / \mathrm{m}^{3}$ of fiber content.

The mix design of control mix was carried out in accordance to ASTM C109M-02 [10]. One part of cement was added to 2.75 parts of sand (by weight), and with a water cement ratio of 0.485 . For mixes with fly ash replacing cement, the used fly ash consisted of materials passing sieve no. 200 and was mixed with the cement. While for mixes containing fly ash replacing sand, the used fly ash consisted of materials retained on sieve no.200 and was mixed with the sand.

After mixing process, the mix was immediately poured into molds within a total elapsed time not exceeding 2 min and $30 \mathrm{sec}$. Casting was carried out in two layers and rodded accordingly. The complete compaction was insured by appearance of a film of cement mortar on the top without appearance of air void. After compaction, the top surface of specimens were trowelled and levelled to obtain smooth surface. After casting, all specimens were kept at room temperature. After 24 hours, the specimens were demolded and cured in a water storage plastic tank. The 30\% of FAcement replacement and 20\% FA-sand replacement were demolded after 48 hours and kept without curing till the 7 th day due to long final set. Expansion of mix and appearance of cracks were observed when the mix was saturated with water at 1,2 , and 5 days of curing after mix.

\section{Results and Discussion}

\subsection{Effect of Cement Replacement with Fly Ash on Flexural Strength}

The flexural strength of the prisms was measured, at 7 and 28 days. Strength of the control mix at 7 days is 7.39 $\mathrm{MPa}$. The value of the flexural strength at 7 days reached the optimum value of $7.98 \mathrm{MPa}$ at $10 \% \mathrm{FA}$, an increase of $8 \%$ was noted. Otherwise, the flexural strength decreases at $20 \%$ and $30 \%$ FA, with a maximum decrease of $20 \%$. A similar trend of results was observed at 28 days.

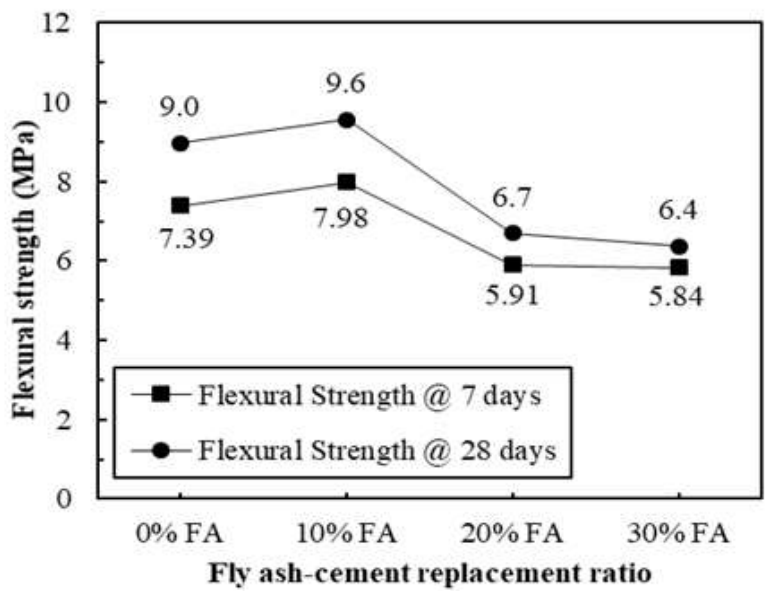

Fig. 2. Flexural Strength versus Fly Ash replaced Cement (FA-C) without Fibers at 7 and 28 days

\subsection{Effect of Sand Replacement with Fly Ash on Flexural Strength}

Flexural strength conducted on mortar specimens with and without fly ash was determined, at 7 and 8 days. At 7 days, it is noted that the flexural strength is quasi similar from $0 \%$ to $20 \%$ FA content. While at 28 days, the flexural strength decreased from $9 \mathrm{MPa}$ (control mix) to $6.6 \mathrm{MPa}(10 \%$ FA content). The strength recovery is $8.4 \mathrm{MPa}$ for $20 \% \mathrm{FA}$ content, which is equivalent to $6.6 \%$ of decreasing of the strength in comparison with the control mix. 


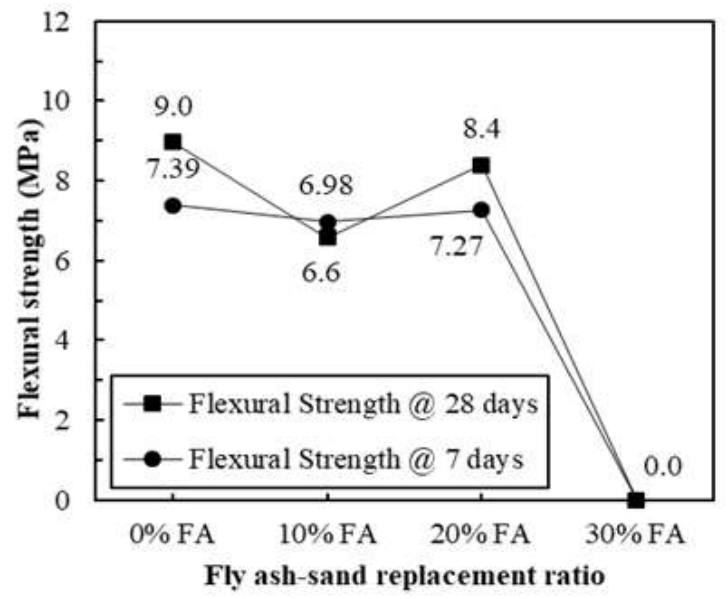

Fig. 3. Flexural Strength versus Fly Ash replaced Sand (FA-S) without Fibers at 7 and 28 days

The flexural strength decreases at 28 days for $10 \%$ FA. The strength at 28 days is lower than that at 7 days. This result may be explained by the fact that the specimens showed micro cracks due to expansion that happened with the contact of curing water for $24 \mathrm{~h}$ age. These cracks had high impact on the flexural strength and low impact on the compressive strength. In addition, for 30\% FA replacing cement, a very low workability was contributed to a mixing failure before testing as shown on the below figure.

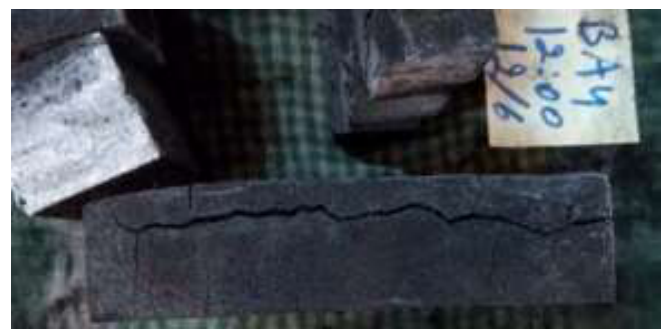

Fig. 4. Crack Development due to Curing for High Content of Fly Ash

\subsection{Effect of PP fibers on flexural strength and energy absorption}

The flexural strength value of prism specimens, at 7 and 28 days, are shown in figure 5 . It is observed that the flexural strength of mortar with different ratios of fibers content: $0.6,1.2$, and $1.8 \mathrm{~kg} / \mathrm{m}^{3}(0.07,0.14$, and $0.21 \%$ by volume) presents a convex trend, at 7 days. Slight variation $(5 \%)$ of the flexural strength was noted with a minimum flexural strength at $0.6 \mathrm{~kg} / \mathrm{m}^{3}$ fiber content and a maximum flexural strength at $1.8 \mathrm{~kg} / \mathrm{m}^{3}$ of fibers content. At 28 days, a slight increase of the flexural strength was observed with the increase of fibers content ranging from 0.6 to $1.8 \mathrm{~kg} / \mathrm{m}^{3}$. However, the control mix presents the higher value at 28 days ( $8.97 \mathrm{MPa})$. 


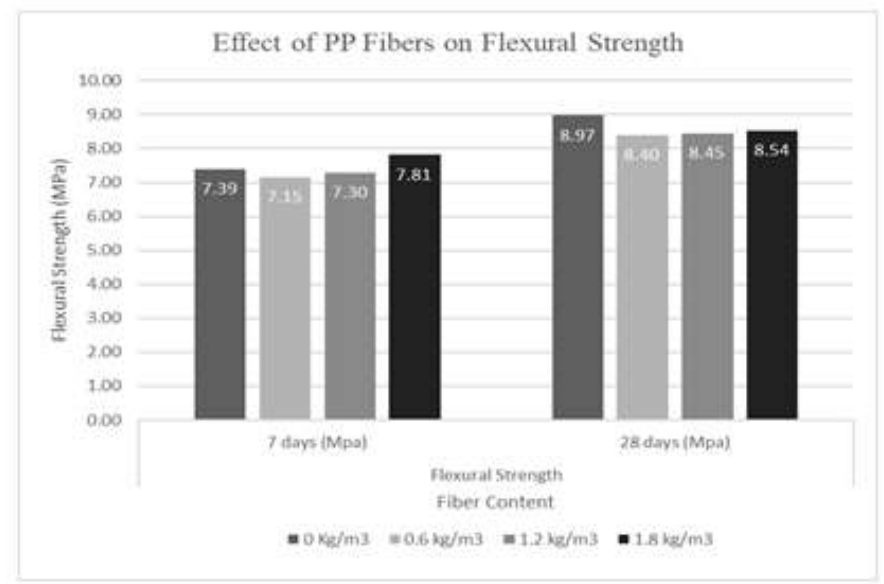

Fig. 5. Effect of PP Fibers on Flexural Strength

In general, the PP fibers are not added to increase the flexural strength but only to increase the post-cracking flexural strength and energy absorption [11]. As shown in figure 6, the vertical displacement versus the applied load was plotted for different ratio of PP fibers content $\left(0,0.6,1.2\right.$, and $\left.1.8 \mathrm{~kg} / \mathrm{m}^{3}\right)$. The area below the curve was calculated to estimate the energy abortion variation with the increase of fiber content. The results indicated an increase of the energy absorption with the fiber content from 0.884 for the control mix to 0.919 for the mix with $1.8 \mathrm{~kg} / \mathrm{m}^{3}$ fiber content.

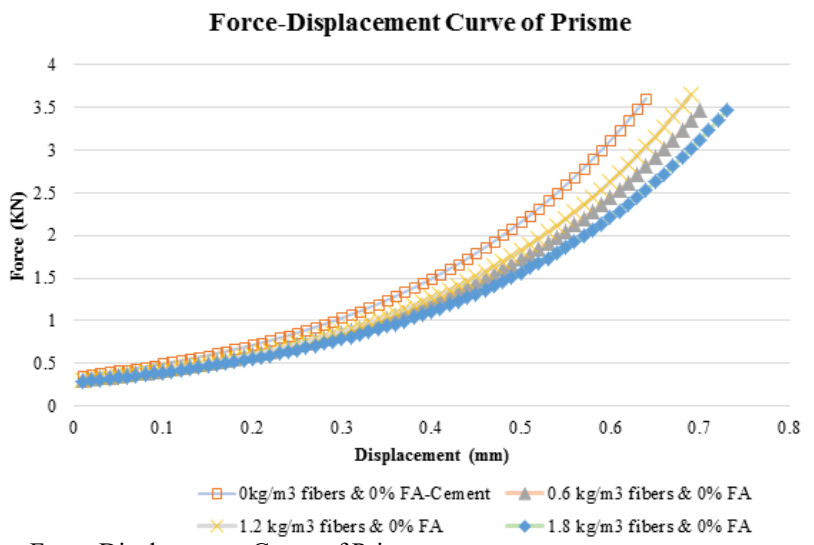

Fig. 6. Effect of PP Fibers on Force-Displacement Curve of Prism

\subsection{Combined effect of PP fibers and cement replacement with fly ash on flexural strength}

The combined effect of PP fibers and FA-C content on the flexural Strength of prism specimens at 7 and 28 days are illustrated in figure 7. At 7 days, the fibers present a slight increasing effect on the flexural strength of mortar without fly ash. For $10 \%$ FA-C, the PP fibers present a negative effect on the flexural strength of mortar, and for $20 \%$ and $30 \%$ FA-C, the flexural strength increased with the fiber content. At 28 days, a similar behaviour is also present, a slight effect of fiber on flexural strength for mortar containing no fly ash, a decrease of flexural strength for $10 \%$ FA-C with the increase of fiber content, and an increase of flexural strength for $20 \%$ FA-C. 


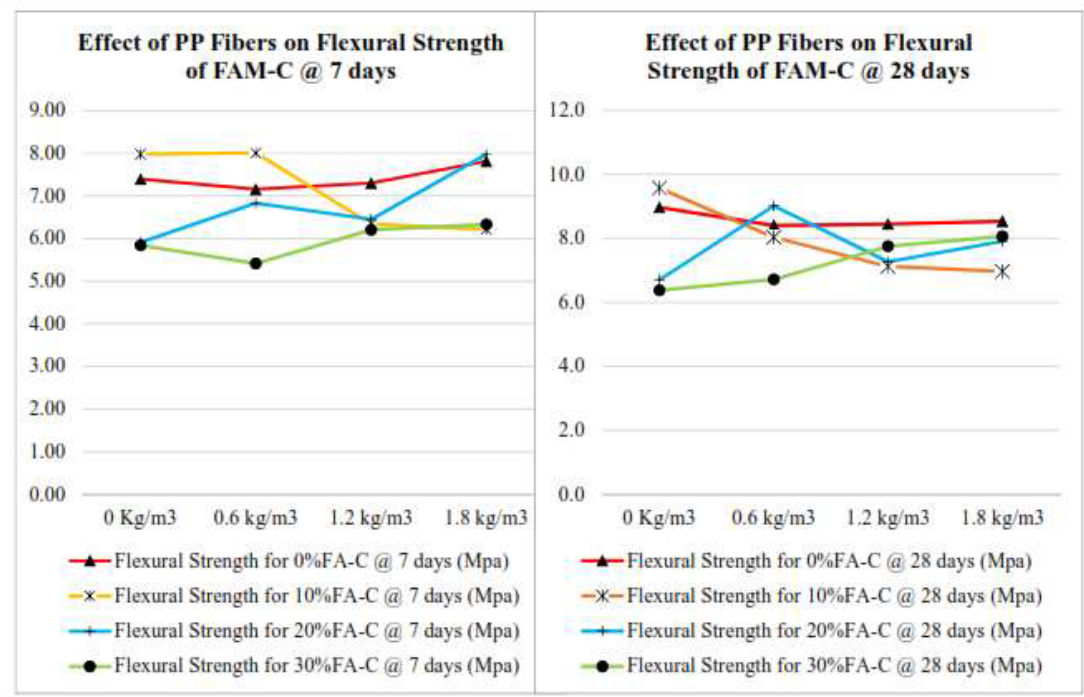

Fig. 7. Effect of PP Fibers on Flexural Strength of FA-C

\subsection{Combined Effect of PP Fibers and Sand Replacement with Fly Ash on Flexural Strength}

The combined effect of PP fibers and FA-S content on the flexural Strength of prisms, at 7 and 28 days, are shown in figure 8. At 7 days, the flexural strength of $0 \%$ FA-S presents a slight increase with the increase of the fiber content, while the $10 \% \mathrm{FA}-\mathrm{S}$ is optimum at $1.2 \mathrm{~kg} / \mathrm{m}^{3}$ of fiber content.

It is shown that the flexural strength downtrend is sharper with the increase of FA-S content, where $0 \%$ FA-S presented a slight increase, $10 \%$ FA-S presented a slight decrease and 20\% FA-S presented a sharp decrease. In general, the increase of PP fibers content presents a negative impact of the flexural strength.

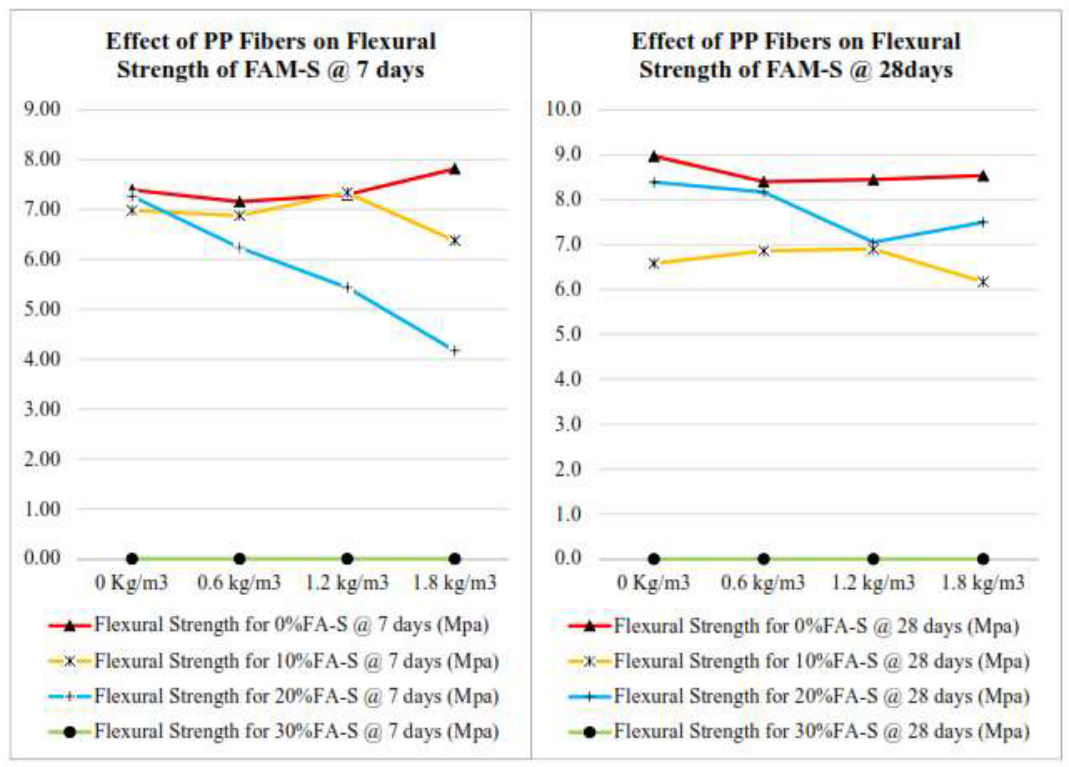

Fig. 8. Effect of PP Fibers on Flexural Strength of FA-S

At 28 days, the effect of PP fibers is not significant for mortar without fly ash with a trend of decreasing of the flexural strength. It should be noted that no flexural strength is higher than the control mix for all mixes replacing sand. The 
$20 \%$ FA-S content presented better results than the $10 \%$ FA-S, due to the presence of cracks before testing in the mix of $20 \%$ FA-S.

\section{Conclusions}

Based on this study, the waste fly ash material presents an effective cement substituent in the range of 10 to $20 \%$. Fly ash replacing sand (FA-S) and cement (FA-C) contributes to higher flexural strength. The flexural strength of mortar decreases with the increase of fly ash replacing cement or sand due to the appearance of cracks. The $20 \%$ FA-S and $30 \%$ FA-C was not cured until 7 days, due to delayed setting time and cracking problems, and the $30 \%$ FA-S presents a very low workability due to low hydration contributing to a mixing failure. Polypropylene fibers has ambiguous effect on the flexural strength. The fibers do not exhibit a net increase of the flexural strength and could present a negative impact on FA-S and FA-C.

\section{References}

1. M. Grzybowski and S. P. Shah, "Shrinkage Craking in Fiber Reinforced Concrete," ACI Materials Journal, vol. 87, pp. 138-148 (1990)

2. B. K. Narenda, "Compressive Strength Development of Fly Ash Concrete for Different Cement Replacement Levels," International Journal of Inventive Engineering and Sciences, vol. 1, no. 6, pp. 0.1-12 (2013)

3. R. O. Lane and J. F. Best, "Properties and Use of Fly Ash in Portland Cement Concrete," Concrete International, vol. 4, pp. 81-92 (1982)

4. A. Harison, "Effect of Fly Ash on Compressive Strength of Portland Pozzolona Cement Concrete," Journal of Academia and Industrial Research (JAIR) (2014)

5. $\quad$ R. Siddique, "Effect of fine aggregate replacement with Class F fly ash on the mechanical properties of concrete," Cement and Concrete Research (2003)

6. A. Salahaldein and s. Muhsen, "Influence of Polypropylene Fiber on Strength of Concrete," American Journal of Engineering Research, vol. 5, no. 7, pp. 223-226 (2016)

7. R. Upadhyay, "Effect of Fly Ash on Flexural Strength of Portland Pozzolona Cement Concrete," Journal of Academia and Industrial Research (JAIR), (2014)

8. ASTM C33, Standard Specification for Concrete Aggregates

9. ASTM C348-14, Standard Test Method for Flexural Strength of Hydraulic-Cement Mortars

10. ASTM C109 M, Standard Test Method for Compressive Strength of Hydraulic Cement Mortars (Using 2-in. or [50-mm] Cube Specimens)

11. A. Sadrmomtazi, A. Fasihi and A. K. Haghi, "Effect of Polypropylene Fibers on mechanical and physical properties of mortars » 3rd International Conference on Concrete \& Development, Tehran (2009) 